\title{
The Mental Status in Patients with Diabetes Mellitus Admitted to a Diabetes Clinic After Presenting in the Emergency Room: The Application of the SCL-90 Scale
}

\author{
Oana Albai' \\ Mirela Frandes $\mathbb{D}^{2}$ \\ Romulus Timar' \\ Bogdan Timar (D) ${ }^{\prime}$ \\ Teodora Anghel ${ }^{3}$ \\ Vlad Florian Avram' \\ Alexandra Sima' \\ 'Department of Internal Medicine, \\ "Victor Babes" University of Medicine \\ and Pharmacy, Timisoara, Romania; \\ ${ }^{2}$ Department of Functional Sciences, \\ "Victor Babes" University of Medicine \\ and Pharmacy, Timisoara, Romania; \\ ${ }^{3}$ Department of Neuroscience, "Victor \\ Babes" University of Medicine and \\ Pharmacy, Timisoara, Romania
}

Background: Diabetes mellitus (DM) is one of the most serious public health problems, involving increasing costs worldwide. The mental state of a person with DM is varied and ever-changing, such as stress, the pressure to always do everything by the book, sadness, anger, and even denial of the disease, all these are feelings patients with DM will experience throughout their life.

Aim: The aim of our study was to assess the presence of mental and psychiatric disorders (anxiety, depressive states, paranoid ideation, phobia, obsessive-compulsive disorder) in a group of patients with DM after hospitalization in the Clinic for Diabetes, Nutrition, and Metabolic Diseases, for various exacerbations of the underlying condition, looking for possible correlations with other cardiovascular risk factors.

Patients and Methods: Clinical and biological parameters, the presence of acute and chronic complications of the diabetic patients have been evaluated. To assess mental health, the symptom checklist (SCL)-90 questionnaire was conducted for all admitted patients.

Results: We observed that the number of patients with obsessive-compulsive disorders was relatively high $(23.3 \%)$, while depression was present in $17.1 \%$ of the patients. Also, $10.6 \%$ of patients had hostility and $15.6 \%$ had delusional ideation. The presence of psychiatric disorders was associated with a higher age (62 vs. 46.5 years; $p<0.001)$, a longer diabetes duration (11 vs. 9 years; $p<0.001$ ), higher fasting glycemia (188 vs. $132 \mathrm{mg} / \mathrm{dL} ; p<0.001$ ) and postprandial glycemia (212 vs. $152 \mathrm{mg} / \mathrm{dL} ; p<0.001)$, and triglycerides (125 vs. $110 \mathrm{mg} /$ $\mathrm{dL} ; p<0.001)$. Patients with altered mental status have shown statistically significantly more altered clinical and biological parameters compared to those without these mental disorders. Conclusion: Patients with DM represent a psychologically vulnerable population, which is why they should undergo early and regular screening for both psychological and psychiatric conditions, especially at admission.

Keywords: mental disorders, cardiovascular risk, cardiovascular risk factors, insulinresistance, compliance, adherence to treatment

\section{Introduction}

Diabetes mellitus (DM) is one of the most important and serious public health problems in the world today. It is estimated that the current number of patients with DM is 463 million worldwide, with a predicted increase to over 700 million by 2045. The largest number of patients with DM belong in the $40-59$ age group, $79 \%$ 
of the adults with DM are living in underdeveloped and developing countries. About $90 \%$ of patients have type 2 DM, and 232 million people remain undiagnosed. ${ }^{1,2}$

The costs involved with this condition will become increasingly difficult to bear, in 2017 alone they exceeded $\$ 800$ billion. ${ }^{3,4} \mathrm{DM}$ is a chronic condition, once it occurs it progresses inexorably, requiring daily treatment, correctly administered throughout an entire life. ${ }^{5}$ It is accompanied by numerous complications, being the leading cause of chronic kidney disease, blindness, and nontraumatic limb amputations. $^{6-9}$ It is considered the equivalent of cardiovascular disease; patients with DM, mainly those with type 2 DM, have several other cardiovascular risk factors: hypertension (HTA), dyslipidemia (increased small and dense LDL particles, triglycerides and apo B, decreased HDL, etc.), obesity, kidney failure, endothelial dysfunction, hypercoagulability, proinflammatory state. ${ }^{10,11}$

DM and psychiatric conditions are closely related, influencing each other through multiple mechanisms. ${ }^{12}$ The mental state of a person with DM is varied and ever-changing, stress, the pressure to always do everything by the book, sadness, anger, and even denial of the diseaseare all feelings patients with DM will experience throughout their life. ${ }^{13-15}$ In these conditions, patients need support from the family, colleagues, friends, and specialized medical care. ${ }^{16-18}$

The presence of psychiatric disorders in patients with $\mathrm{DM}$ is accompanied by a decrease in their quality of life, increased costs as well as lower treatment adherence. Also, a suboptimal glycemic control, a higher frequency of hospitalizations, and acute metabolic decompensations were found in these patients. ${ }^{19,20}$

The main mechanism by which mental disorders increase the risk for or worsen existing cardiovascular disease is the alteration of the quality of life and the reduction of treatment compliance. ${ }^{21-23}$ Mental disorders have been shown to accompany an unhealthy lifestyle: hypercaloric diet increased consumption of salt and saturated fat, smoking, reduced physical exercise, reduced compliance with treatment. The risk of myocardial infarction and stroke increases 10-fold in patients who do not comply with the physician's recommendations. ${ }^{24,25}$ It is known that counterregulatory hormones are released under stress conditions: cortisol, adrenaline, etc. Increased levels of cortisol cause an increase in blood sugar, weight, small and dense LDL particles, blood pressure. A higher adrenaline level increases resting heart rate, blood pressure, thus being responsible for the increased risk of myocardial infarction, arrhythmias, and heart failure. ${ }^{26,27}$

Inflammation caused by depressive conditions appears to play an extremely important role in increasing cardiovascular risk; depression increases platelet activity, amplifying the risk of coronary artery disease. ${ }^{28,29}$

Given these considerations, the main purpose of the present study is to assess the presence of psychiatric disorders (anxiety, states of depression, paranoid ideation, phobia, obsessive-compulsive disorder) in a group of DM patients at admission in the Clinic for Diabetes, Nutrition and Metabolic Diseases, for various exacerbations and decompensations of the underlying disease. We also monitored possible correlations between the presence of cardiovascular disease and the psychiatric disorders we investigated, trying to identify the presence and association of several cardiovascular risk factors.

\section{Patients and Methods}

\section{Study Design and Patients}

The study included 1419 patients with DM hospitalized in the Clinic for Diabetes, Nutrition, and Metabolic Diseases of the Emergency County Hospital from Timisoara, Romania between 2015 and 2018. The included patients who needed hospitalization for various metabolic disorders: either hypoglycemia or hyperglycemia, caused by various conditions. In the case of patients with DM, these situations are quite common, especially in conditions where a strict diet is not followed and where there is a poor adherence to treatment.

This study was conducted in accordance with the Declaration of Helsinki, and the protocol of our study was approved by the Ethics Committee of the Emergency County Hospital Timisoara. All patients included in the study provided written informed consent for the acquisition, analysis, and publication of the anonymous data collected during their hospital admission.

The exclusion criteria were: under 18 years of age, presence of chronic kidney disease (estimated glomerular filtration rate under $45 \mathrm{~mL} / \mathrm{min} / 1.73 \mathrm{~m}^{2}$ or renal replacement therapy), presence of severe psychiatric disorders, or acute cardiovascular events.

\section{Clinical, Anthropometric, and Laboratory Data}

We collected and evaluated anthropometric parameters (size, weight, body mass index [BMI], waist circumference 
[WC], data regarding family history, personal medical history, alcohol consumption, smoking. Glycemic control (fasting glycemia, postprandial glycemia, $\mathrm{HbA1c}$ ), lipid profile (total cholesterol [CT], triglycerides - TG, HDLc, LDLc), renal function (urea, creatinine, urinalysis, urinary albumin/ creatinine ratio, proteinuria, uric acid), and hepatic function were evaluated. Microangiopathic, macroangiopathic, and neuropathic complications have also been assessed.

\section{Assessment of Neurological Characteristics}

The standard Mini-Mental State Examination (MMSE) form was administered to the patients included in the study. The score of MMSE ranges from 0 to 30 points, where lower scores indicate poor cognitive performance, and higher scores indicate better cognitive performance. The MMSE form includes 19 questions which evaluate the patient's mental status. It includes the following 5 categories: 10 questions related to orientation (year, season, date, day, month, state, city, close street, floor, and location), 2 items about memory (repeat the words car, window, and vase, and thereafter a delayed recall), 1 item regarding calculation, 5 language items, and 1 constructional item (to copy overlapping pentagons). ${ }^{30}$

We employed the Romanian version of the standard MMSE test, taking into account the following cutoff scores for the classification of cognitive impairment: scores $>27$ indicate normal cognition, scores between 21 and 26 indicate mild cognitive impairment, scores between 11 and 20 indicate moderate cognitive impairment, and scores below than 10 severe cognitive impairment. ${ }^{31}$

\section{SCL-90 Questionnaire}

To assess mental health, the symptom checklist (SCL)-90 questionnaire, a multidimensional symptom self-assessment inventory developed by Derogatis, was conducted for all admitted patients. The main purpose of the current version of the SCL-90-R scale is to be used as a screening tool to evaluate the type and severity of various mental symptoms. The scale includes 90 items chosen mainly from the Cornell Medical Index scale and other scales, items covering 9 symptomatic areas (somatization, obsession-compulsion, interpersonal sensitivity, depression, anxiety, hostility, phobia-anxiety, paranoid ideation, and psychoticism) and 3 global indices of psychological distress. The scale applies to the subject as a self-questioner, and it takes 15 minutes to fill it out. The degree of psychological distress and discomfort is scored on a 5-point Likert scale,from none $=0$ to extreme $=4$ and refers to the last 7 days (one week) of the subject's life. There is also a short version of only 53 items called Brief Symptom Inventory or Harvard Subscale for Anxiety, Harvard Subscale for Depression, phobia, or discomfort. ${ }^{32-34}$

\section{Statistical Analysis}

Data were analysed using the SPSS v.20 software (SPSS Inc., Chicago, IL, USA) and the R software for statistical computing. The threshold for statistical significance was a $p$-value $<0.05$, and a value of 0.95 was the confidence level for estimating intervals.

Continuous data normally distributed (following a Gaussian distribution) were presented as mean and standard deviation, while continuous data following other distributions were described as median and interquartile range. Nominal data were described as absolute frequency and percentage. The normality of continuous data distributions was verified by applying the Kolmogorov-Smirnov's test, while the equality of variances was tested using Levene's test.

The significance of the differences between groups of patients with sarcoidosis was assessed using the Student's $t$-test, in the case of Gaussian populations, while the MannWhitney $U$-test was used in case of non-Gaussian populations. To assess the statistical significance of the difference between percentages, the Pearson chi-square or Fisher's exact test was employed. For comparison of more than two groups of patients with sarcoidosis, one-way ANOVA for continuous variables with gaussian distribution or Kruskal-Wallis $H$-test for continuous variables with non-gaussian distribution was applied.

The influence of one or more confounding factors in dichotomous outcomes was evaluated by applying univariate and multivariate logistic regression models. The model's goodness-of-fit was computed using Nagelkerke's $\mathrm{R}^{2}$ method. The linearity of the continuous variables with respect to the logit of the dependent variable was assessed through the Box-Tidwell procedure.

\section{Results}

\section{Patient Characteristics}

The study included 1419 patients with DM with a mean age of $53.61( \pm 12.61)$ years and a mean duration of the disease of $11.03( \pm 5.12)$ years, admitted to the Clinic for Diabetes, Nutrition, and Metabolic Diseases. There were 12.9\% patients with type $1 \mathrm{DM}$ and $87.1 \%$ patients with type 2 DM (Table 1). 
Table I Baseline Characteristics of the Patients with DM

\begin{tabular}{|c|c|}
\hline Parameters & Patients with DM $(N=1419)$ \\
\hline Age (years) ${ }^{\mathrm{a}}$ & $53.61( \pm 12.61)$ \\
\hline Sex $[M]^{c}$ & $633(44.6 \%)$ \\
\hline Type 2 DM $^{\text {c }}$ & $1236(87.1 \%)$ \\
\hline Duration of DM (years) ${ }^{b}$ & $10.00(8.00-14.00)$ \\
\hline Alcohol consumption ${ }^{c}$ & 396 (27.9\%) \\
\hline Smoking ${ }^{c}$ & $558(39.3 \%)$ \\
\hline Cardiovascular disease $^{c}$ & $420(29.6 \%)$ \\
\hline Chronic kidney disease $^{c}$ & $342(24.1 \%)$ \\
\hline BMI $\left(\mathrm{kg} / \mathrm{m}^{2}\right)^{\mathrm{b}}$ & $28.00(24.00-31.00)$ \\
\hline Waist circumference $(\mathrm{cm})^{\mathrm{b}}$ & $100.00(85.00-108.00)$ \\
\hline \multicolumn{2}{|l|}{ Lipid profile } \\
\hline Total cholesterol $(\mathrm{mg} / \mathrm{dL})^{\mathrm{b}}$ & $185.00(159.00-220.00)$ \\
\hline $\mathrm{HDLc}(\mathrm{mg} / \mathrm{dL})^{\mathrm{b}}$ & $46.00(36.00-57.00)$ \\
\hline $\operatorname{LDLc}(\mathrm{mg} / \mathrm{dL})^{\mathrm{b}}$ & $108.00(83.20-140.60)$ \\
\hline Triglycerides $(\mathrm{mg} / \mathrm{dL})^{\mathrm{b}}$ & $112.00(87.00-160.00)$ \\
\hline Glucose control & \\
\hline Fasting glycemia $(\mathrm{mg} / \mathrm{dL})^{\mathrm{b}}$ & $153.00(117.00-221.00)$ \\
\hline Postprandial glycemia $(\mathrm{mg} / \mathrm{dL})^{\mathrm{b}}$ & $200.00(130.00-233.00)$ \\
\hline $\mathrm{HbAlc}(\%)^{\mathrm{b}}$ & $9.00(8.40-10.00)$ \\
\hline \multicolumn{2}{|l|}{ Complications of DM } \\
\hline Diabetic peripheral polyneuropathy ${ }^{c}$ & 750 (52.9\%) \\
\hline Diabetic arteriopathy $^{c}$ & $120(8.4 \%)$ \\
\hline Diabetic retinopathy ${ }^{c}$ & $294(20.7 \%)$ \\
\hline Pancreatitis ${ }^{c}$ & $96(6.8 \%)$ \\
\hline Cholelithiasis $^{c}$ & $192(13.5 \%)$ \\
\hline \multicolumn{2}{|l|}{ Neurological } \\
\hline MMSE score ${ }^{\mathrm{b}}$ & $24.00(19.00-30.00)$ \\
\hline Previous stroke ${ }^{c}$ & $57(4 \%)$ \\
\hline Dementia $^{c}$ & 87 (6.1\%) \\
\hline
\end{tabular}

Notes: a Continuous variables (with Gaussian distribution) are indicated by their mean (standard deviation); ${ }^{b}$ continuous variables (with non-Gaussian distribution) are indicated by their median (interquartile range); ${ }^{c}$ categorical variables are presented by absolute frequency (percentage) in the sample.

Abbreviations: DM, diabetes mellitus; BMI, body mass index; HDLc, high-density lipoprotein cholesterol; LDLc, low-density lipoprotein cholesterol; HbAIc, hemoglobin Alc; MMSE, Mini-Mental State Examination.

\section{Assessment of Psychiatric Disorders}

We observed that only a small percentage of patients $(0.6 \%)$ had somatic disorders. Instead, the number of patients with obsessive-compulsive disorders was higher (23.7\%). Regarding depression, we observed that $15.2 \%$ of the patients had average depression levels and $2.3 \%$ of patients had high depression levels (Table 2).

Anxiety disorders were reduced, with only $3 \%$ of patients presenting average levels of anxiety and $0.6 \%$
Table 2 Presence of Moderate Psychiatric Disorders

\begin{tabular}{|c|c|}
\hline SCL-90 Categories ${ }^{a}$ & Patients with DM $(N=1419)$ \\
\hline Somatization & $9(0.6 \%)$ \\
\hline Obsessive-compulsive & 336 (23.7\%) \\
\hline Sensitivity & $345(24.3 \%)$ \\
\hline Depression & $216(15.2 \%)$ \\
\hline Anxiety & $42(3 \%)$ \\
\hline Hostility & $150(10.6 \%)$ \\
\hline Phobic/anxious & $0(0 \%)$ \\
\hline Paranoid ideation & 225 (I5.9\%) \\
\hline Psychoticism & $3(0.2 \%)$ \\
\hline
\end{tabular}

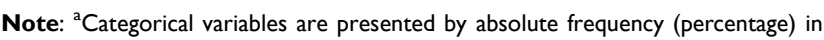
the sample.

Abbreviations: SCL, symptom checklist; DM, diabetes mellitus.

elevated levels. Moreover, $0.6 \%$ of patients had high levels of psychiatric disorders. Also, $10.6 \%$ of patients had hostility and $15.6 \%$ had delusional ideation. We observed that patients with depression had a significantly lower quality of life profile than patients without depression.

\section{Assessment of Lipid and Glycemic Profile}

We considered the presence of a disorder if a patient experienced at least one category of disorders from the SCL-90 categories. We compared glycemic and lipid profiles in patients with at least one moderate or severe disorder and in patients who had reduced or no disorders at all. We observed that patients with moderate and severe disorders had a significantly more altered lipid profile than those without such disorders (Table 3).

\section{Assessment of Cardiovascular Risk Factors}

Deriving univariate logistic regression models, we identify the duration of $\mathrm{DM}$ as a significant risk factor for the presence of moderate and severe psychiatric disorders $(\mathrm{OR}=1.093,95 \%$ CI: $1.065-1.123, \mathrm{p}<0.001)$. We noticed that alcohol consumption is a significant risk factor $(\mathrm{OR}=$ $1.706,95 \%$ CI: $1.348-2.159, \mathrm{p}<0.001$ ), as well as smoking $(\mathrm{OR}=2.241,95 \% \mathrm{CI}: 1.802-2.788, \mathrm{p}<0.001)$. We also observed that $\mathrm{BMI}$ and $\mathrm{WC}$ were significant risk factors, $\mathrm{OR}=1.023,95 \% \mathrm{CI}: 1.002-1.045, \mathrm{p}=0.035$ and $\mathrm{OR}=1.017,95 \% \mathrm{CI}: 1.011-1.023, \mathrm{p}<0.001$, respectively. Regarding lipid profile, we observed that elevated HDLc values were a protective factor ( $\mathrm{OR}=0.916,95 \%$ CI: $0.909-0.923, p<0.001)$. Conversely, elevated LDLc values were not a significant risk factor $(\mathrm{OR}=1.003,95 \%$ CI: $1.001-1.006, \mathrm{p}=0.151)$. We also found that 
Table 3 Lipid and Glycemic Profile in Patients with DM and Psychiatric Disorders Compared to Patients with DM and No Psychiatric Disorders

\begin{tabular}{|c|c|c|c|}
\hline Parameter $^{\mathbf{a}}$ & $\begin{array}{c}\text { Patients with DM and Psychiatric } \\
\text { Disorders }\end{array}$ & $\begin{array}{c}\text { Patients with DM without Psychiatric } \\
\text { Disorders }\end{array}$ & p-value ${ }^{b}$ \\
\hline Number (\%) & 705 (49.7\%) & $714(50.3 \%)$ & - \\
\hline Age (years) & $62.00(54.00-65.00)$ & $46.50(38.50-54.00)$ & $<0.001$ \\
\hline Duration of DM (years) & II.00 (8.00-14.00) & $9.00(7.00-11.50)$ & $<0.001$ \\
\hline BMI $\left(\mathrm{kg} / \mathrm{m}^{2}\right)$ & $28.00(25.00-31.00)$ & $27.00(23.00-31.00)$ & 0.029 \\
\hline$W C(\mathrm{~cm})$ & $100.00(91.00-109.00)$ & $93.00(80.00-107.00)$ & $<0.001$ \\
\hline Fasting glycemia (mg/dL) & $188.00(\mid 34.00-248.00)$ & | $32.00(97.00-180.00)$ & $<0.001$ \\
\hline Postprandial glycemia (mg/dL) & $212.00(170.00-250.00)$ & $158.00(\mid 20.00-216.00)$ & 0.001 \\
\hline $\mathrm{HbAlc}(\%)$ & $9.00(8.40-10.20)$ & $8.80(8.25-9.65)$ & 0.003 \\
\hline Triglycerides (mg/dL) & $125.00(95.00-168.00)$ & $110.00(84.00-137.00)$ & $<0.001$ \\
\hline HDLc (mg/dL) & $40.00(35.00-56.00)$ & $48.00(36.00-60.00)$ & $<0.001$ \\
\hline LDLc (mg/dL) & III.40 (83.20-140.60) & $105.80(88.00-151.40)$ & 0.370 \\
\hline
\end{tabular}

Notes: ${ }^{a}$ Continuous variables (with non-Gaussian distribution) are indicated by their median (interquartile range); ${ }^{b}$ independent samples, Mann-Whitney $U$-test. Abbreviations: DM, diabetes mellitus; BMI, body mass index; WC, waist circumference; HbA Ic, hemoglobin Alc; HDLc, high-density lipoprotein cholesterol; LDLc, lowdensity lipoprotein cholesterol.

triglycerides were not a risk factor. Regarding glycemic profile, we observed that elevated fasting glycemia values constituted a significant risk factor $(\mathrm{OR}=1.010,95 \% \mathrm{CI}$ : $1.008-1.012, \mathrm{p}<0.001)$. Postprandial glycemia was also a risk factor $(\mathrm{OR}=1.006,95 \% \mathrm{CI}: 1.005-1.007, \mathrm{p}<0.001)$ (Table 4).

We constructed logistic regression models to determine the effects of different parameters of the lipid and the glycemic profile in patients with DM on the probability to develop moderate and severe psychiatric disorders. Continuous type variables were tested in terms of linearity following the Box-Tidwell procedure. We applied a
Bonferroni correction, and the statistical significance threshold was $p<0.004$. The final regression model was statistically significant, $\chi 2(11)=450.901, p<0.001$, with a Nagelkerke coefficient $R^{2}=0.442$ so that the model explained $44.2 \%$ of the variant of the presence of moderate and severe psychiatric disorders among patients with DM. Moreover, the Hosmer and Lemeshow goodness of fit test indicated that the proposed model was suitable.

We noticed that a long DM duration is associated with 1.12 times higher odds of developing psychiatric disorders than a short $\mathrm{DM}$ duration $(\mathrm{OR}=1.120,95 \% \mathrm{CI}: 1.084$ 1.158) (Table 4) and WC was also a significant risk factor

Table 4 Predictors of Moderate to Severe Mental Disorders in Patients with DM (Multivariate Logistic Regression Model; Nagelkerke $\left.\mathrm{R}^{2}=0.442\right)$

\begin{tabular}{|c|c|c|c|c|c|c|}
\hline \multirow[t]{2}{*}{ Variable Predictor } & \multirow[t]{2}{*}{ Crude OR } & \multicolumn{2}{|c|}{$95 \% \mathrm{Cl}$} & \multirow[t]{2}{*}{ Adjusted OR } & \multicolumn{2}{|c|}{$95 \% \mathrm{Cl}$} \\
\hline & & Lower & Upper & & Lower & Upper \\
\hline Duration of DM* & 1.093 & 1.065 & 1.123 & 1.120 & $\mathrm{I} .084$ & 1.158 \\
\hline BMI & 1.023 & 1.002 & 1.045 & 1.031 & 0.980 & 1.085 \\
\hline WC* & 1.017 & 1.011 & 1.023 & 1.036 & 1.022 & 1.050 \\
\hline Alcohol consumption* & 1.706 & 1.348 & 2.159 & 2.390 & 1.612 & 3.544 \\
\hline Smoking* & 2.241 & 1.802 & 2.788 & 2.499 & 1.805 & 3.459 \\
\hline Fasting glycemia* & 1.010 & 1.008 & 1.012 & 1.010 & $\mathrm{I} .007$ & 1.012 \\
\hline Postprandial glycemia* & 1.006 & 1.005 & 1.007 & 1.006 & 1.003 & 1.008 \\
\hline $\mathrm{HbAlc}$ & 1.000 & 0.988 & 1.012 & 1.070 & 0.962 & 1.191 \\
\hline Triglycerides & 0.997 & 0.996 & 1.001 & 1.023 & 0.993 & 1.121 \\
\hline HDLc & 0.916 & 0.909 & 0.923 & 0.996 & 0.993 & 0.998 \\
\hline LDLc & 1.003 & 1.001 & 1.006 & 1.024 & 1.014 & 1.034 \\
\hline
\end{tabular}

Note: *Predictor variable is significant both independently and as a co-factor.

Abbreviations: DM, diabetes mellitus; BMI, body mass index; WC, waist circumference; HDLc, high-density lipoprotein cholesterol; LDLc, low-density lipoprotein cholesterol. 
$(\mathrm{OR}=1.036,95 \% \mathrm{CI}: 1.022-1.050)$. We noticed that patients with alcohol consumption have 2.39 times higher odds of developing psychiatric disorders than patients who do not drink alcohol. Also, smokers have 2.499 times higher odds of developing disorders than non-smokers. We observed that triglycerides level was neither a protective nor a risk factor. A higher HDLc was associated with a decreased likelihood of developing moderate or severe psychiatric disorders ( $\mathrm{OR}=0.996,95 \% \mathrm{CI}$ : 0.993-0.998), whereas higher LDLc was correlated with an increased likelihood of moderate and severe psychiatric disorders $(\mathrm{OR}=1.024,95 \%$ CI: 1.014-1.034).

\section{Discussion}

DM is characterized by chronic hyperglycemia, often with high glycemic variability, responsible for the acute and chronic complications of the disease. ${ }^{35}$ On the other hand, changes in mental state cause significant glycemic imbalances. ${ }^{36,37}$ Knowing that the therapeutic success of diseases also depends on the mental state of patients, we considered it extremely useful to assess their mental status, especially in stressful conditions.

$\mathrm{DM}$ is one of the most serious and incurable chronic conditions, causing changes in the psychological sphere of patients. Permanent self-monitoring, strict calculation of carbohydrate requirements, mealtimes, injectable treatment, exercise dosage and many other aspects of the disease cause permanent tension, emotional control, permanent stress, which is reflected on the personality of the patient with DM. ${ }^{38-40}$

Studying the psychological particularity of patients with DM is of major practical importance because it can help both the patient and the physician, who develops the treatment strategy. Knowledge, analysis of important psychological characteristics of the factors that determine disorder behaviors of the patient with DM, which may improve or worsen the mental state, can influence the evolution of the disease. ${ }^{41,42}$

Mental disorders play an extremely important role in global mortality, so $14.3 \%$ of deaths worldwide (about 8 million deaths annually) are due to psychiatric conditions. The presence of psychiatric conditions increases the relative risk of all-cause mortality by $2.22 \%$. Patients with psychiatric disorders had a life expectancy that is shorter by 8 to 20 years, compared to the general population and they die due to cardiovascular diseases, neoplasia, and lung diseases. ${ }^{43-45}$
We observed that $49.7 \%$ of the DM patients hospitalized after addressing the emergency room presented psychiatric disorders. Accordingly, recent studies in Asia have shown a fairly high prevalence of psychiatric disorders in patients with DM. Khuwaja et al described a prevalence of $44 \%$ for depression and $58 \%$ for anxiety. ${ }^{46}$ Although studies in Western countries have found a lower prevalence, Collins et al revealed prevalence values of $32 \%$ for depression and $22.4 \%$ for anxiety. ${ }^{47}$

In a study involving 940 patients with stable coronary artery disease, Gehi et al showed that the number of patients who did not comply with the drug recommendations was 3 times higher in the group with major symptoms of depression than in the group with minimal symptoms. ${ }^{48}$ Rieckmann et al found that patients with depressive symptoms were non-adherent to aspirin treatment, this non-adherence increasing directly with the severity of depression. ${ }^{49}$

Studies conducted by Carliner et al published between 1986 and 2013, regarding the prevalence of cardiovascular risk factors in patients with bipolar disorder and schizophrenia showed an increase in obesity and DM in Africans, white Americans, and Non-Hispanics. ${ }^{50}$ Recent meta-analysis data including several studies have demonstrated a strong association between the presence of metabolic syndrome and psychiatric disorders. ${ }^{51,52}$

Anxiety, schizophrenia, bipolar disorder, or other psychiatric disorders are among the top 20 causes of disability. Actual data suggest that in 2030, depression will become a major cause of disability worldwide. Depression is 3 times more frequent in patients who have had a myocardial infarction compared to the general population. $^{53,54}$ Also, approximately $15-30 \%$ of patients with cardiovascular disease are diagnosed with depression. In the PREMIER study, in hospitalized patients who had an acute myocardial infarction, a 3-fold higher frequency of depression was observed in women younger than 60 years of age, compared to men over 60 years of age. ${ }^{55}$

\section{Relevance of Findings}

We consider that mental state examination is analogous to somatic state examination. Therefore, due to the negative impact of cognitive disorders on the quality of life and adherence to treatment, it is necessary to correctly evaluate patients regarding their mental and psychiatric status, especially after emergencies, when a treatment program has to be established. One limitation of our study was that no pre-admission mental health status was included. 


\section{Future Perspectives}

We intend to continue with the investigations regarding the mental status of the patients. It is extremely useful to implement questionnaires to assess the mental status that is as easy as possible, both for the physician and the patient.

\section{Conclusions}

Many patients with psychiatric disorders remain undiagnosed even if patients with DM represent a psychologically vulnerable population. They should be screened early and regularly for both psychological and psychiatric conditions (anxiety, depression, phobia, obsession, hostility), at admission in order to receive proper treatment as soon as possible. We observed that anxiety, schizophrenia, bipolar disorder are among the more frequent causes of psychiatric disorders at admission. Actual data suggest that in the coming years, psychiatric disorders will become major causes of disability worldwide.

\section{Disclosure}

The authors declared no conflicts of interest for this work.

\section{References}

1. IDF Diabetes Atlas 9th Edition 2019 and other resources Available from: www.diabetesatlas.org. Accessed April 1, 2021.

2. Saeedi P, Petersohn I, Salpea P, et al. Global and regional diabetes prevalence estimates for 2019 and projections for 2030 and 2045 : results from the International Diabetes Federation Diabetes Atlas, 9th edition. Diabetes Res Clin Pract. 2019;157:107843.

3. American Diabetes Association. Economic costs of diabetes in the U. S. in 2017. Diabetes Care. 2018;41:917-928.

4. Riddle MC, Herman WH. The cost of diabetes care - $\mathrm{n}$ elephant in the room. Diabetes Care. 2018;41(5):929-932.

5. Harding JL, Pavkov ME, Magliano DJ, Shaw JE, Gregg EW. Global trends in diabetes complications: a review of current evidence. Diabetologia. 2019;62:3-16.

6. Murphy D, McCulloch CE, Lin F, et al. Trends in prevalence of chronic kidney disease in the United States. Ann Intern Med. 2016;165:473-481.

7. United States Renal Data System. 2014 USRDS Annual Data Report: Epidemiology of Kidney Disease in the United States. Bethesda, MD: National Institutes of Health, National Institute of Diabetes and Digestive and Kidney Diseases; 2014:188-210.

8. Bourne RR, Stevens GA, White RA, et al. Causes of vision loss worldwide, 1990-2010: a systematic analysis. Lancet Global Health. 2013;1:e339-e349.

9. American Diabetes Association. Microvascular complications and foot care: standards of medical care in diabetes - 2019. Diabetes Care. 2019;42(Supplement 1):S124-S138.

10. Sarwar N, Gao P, Seshasai SR, et al. Diabetes mellitus, fasting blood glucose concentration, and risk of vascular disease: a collaborative meta-analysis of 102 prospective studies. Emerging risk factors collaboration. Lancet. 2010;375:2215-2222.

11. Rawshani A, Sattar N, Franzén S, et al. Excess mortality and cardiovascular disease in young adults with type 1 diabetes in relation to age at onset: a nationwide, register-based cohort study. Lancet. 2018;392:477-486.
12. Dimsdale JE. Psychological stress and cardiovascular disease. J Am Coll Cardiol. 2008;51(13):1237-1246.

13. Rotella F, Mannucci E. Depression as a risk factor for diabetes: a metaanalysis of longitudinal studies. J Clin Psychiatry. 2013;74:3137.

14. Albai O, Frandes M, Timar R, Roman D, Timar B. Risk factors for developing dementia in type 2 diabetes mellitus patients with mild cognitive impairment. Neuropsychiatr Dis Treat. 2019;15:167-175.

15. Bajor LA, Gunzler D, Einstadter D, et al. Associations between comorbid anxiety, diabetes control, and overall medical burden in patients with serious mental illness and diabetes. Int $J$ Psychiatry Med. 2015;49:309-320.

16. Huang Y, Wei X, Wu T, et al. Collaborative care for patients with depression and diabetes mellitus: a systematic review and metaanalysis. BMC Psychiatry. 2013;13:260.

17. Anderson RJ, Freedland KE, Clouse RE, Lustman PJ. The prevalence of comorbid depression in adults with diabetes: a meta-analysis. Diabetes Care. 2001;24:1069-1078.

18. de Groot M, Golden SH, Wagner J. Psychological conditions in adults with diabetes. Am Psychol. 2016;71(7):552-562.

19. Winchester RJ, Williams JS, Wolfman TE, et al. Depressive symptoms, serious psychological distress, diabetes distress, and cardiovascular risk factor control in patients with type 2 diabetes. J Diabetes Complications. 2016;30:312-317.

20. Allison DB, Newcomer JW, Dunn AL, et al. Obesity among those with mental disorders. A national institute of mental health meeting report. Am J Prev Med. 2009;36(4):341-350.

21. Lane JD, McCaskill CC, Williams PG, et al. Personality correlates of glycemic control in type 2 diabetes. Diabetes Care. 2000;23:13211325.

22. Gonzalez JS, Peyrot M, McCarl LA, et al. Depression, and diabetes treatment nonadherence: a meta-analysis. Diabetes Care. 2008;31:2398-2403.

23. Egede LE, Grubaugh AL, Ellis C. The effect of major depression on preventive care and quality of life among adults with diabetes. Gen Hosp Psychiatry. 2010;32:563-569.

24. Lustman PJ, Anderson RJ, Freedland KE, de Groot M, Carney RM. Depression and poor glycemic control: a meta-analytic review of the literature. Diabetes Care. 2000;23:434-442.

25. Sheps D, McMahon R, Becker L, et al. Mental stress-induced ischemia and all-cause mortality in patients with coronary artery disease: results from the psychophysiological investigations of myocardial ischemia study. Circulation. 2002;105:1780-1784.

26. Anderson RJ, Freedland KE, Clouse RE, Lustman PJ. The prevalence of comorbid depression in adults with diabetes: a meta-analysis. Diabetes Care. 2001;24:1069-1078.

27. Ciechanowski PS, Katon WJ, Russo JE. Depression and diabetes: impact of depression symptoms on adherence, function, costs. Arch Intern Med. 2000;160:3278-3285.

28. Halaris A. Inflammation-associated co-morbidity between depression and cardiovascular disease. Cogn Affect Behav Neurosci. 2017;31:45-70.

29. AbuRuz ME, Al-Dweik G. Depressive symptoms and complications early after acute myocardial infarction: gender differences. Open Nurs J. 2018;12:205-214.

30. Pangman VC, Sloan J, Guse L. An examination of psychometric properties of the mini-mental status examination and the standardized mini-mental status examination: implications for clinical practice. Appl Nurs Res. 2000;13(4):209-213.

31. Folstein MF, Folstein SE, McHugh PR. The "mini-mental state". A practical method for grading the cognitive state of the patients for the clinician. J Psychiatr Res. 1975;12:189-198.

32. Derogatis LR. The SCL-90 Manual I; Scoring, Administration and Procedures for the SCL-90. Baltimore: John Hpkins University School of Medicine, Clinical Psychometrics Unit; 1977. 
33. Derogatis LR, Cleary PA. Conformation of the dimensional structure of the SCL90: a study in construct validity. J Clin Psychol. 1977;33:981-989.

34. Weissman MM, Sholomskas D, Pottenger M, Prusoff BA, Locke BZ. Assessing depressive symptoms in five psychiatric populations: a validation study. Am J Epidemiol. 1977;106(3):203-214.

35. Ceriello A, Ihnat MA. 'Glycaemic variability': a new therapeutic challenge in diabetes and the critical care setting. Diabet Med. 2010;27(8):862-867.

36. Lustman PJ, Anderson RJ, Freedland KE, de Groot M, Carney RM. Depression and poor glycemic control: a meta-analytic review of the literature. Diabetes Care. 2000;23:934-942.

37. Khuwaja AK, Lalani S, Dhanani R, Azam IS, Rafique G, White F. Anxiety and depression among outpatients with type 2 diabetes: a multi-centre study of prevalence and associated factors. Diabetol Metab Syndr. 2010;2:72.

38. Anderson RJ, Grigsby AB, Freedland KE, et al. Anxiety and poor glycemic control: a meta-analytic review of the literature. Int $J$ Psychiatry Med. 2002;32:235-247.

39. Robertson SM, Stanley MA, Cully JA, Naik AD. Positive emotional health and diabetes care: concepts, measurement, and clinical implications. Psychosomatics. 2012;53:1-12.

40. Stuckey HL, Mullan-Jensen CB, Reach G, et al. Personal accounts of the negative and adaptive psychosocial experiences of people with diabetes in the second Diabetes Attitudes, Wishes and Needs (DAWN2) study. Diabetes Care. 2014;37:2466-2474.

41. Peyrot M, Rubin RR. Behavioral and psychosocial interventions in diabetes: a conceptual review. Diabetes Care. 2007;30(10):2433-2440.

42. Kalra B, Kalra S, Balhara YP. Psychological assessment and management in diabetes. J Pak Med Assoc. 2013;63:1555-1557.

43. Walker ER, McGee RE, Druss BG. Mortality in mental disorders and global disease burden implications: a systematic review and metaanalysis. JAMA Psychiatry. 2015;72(4):334-341.

44. Wahlbeck K, Westman J, Nordentoft M, Gissler M, Laursen TM. Outcomes of Nordic mental health systems: life expectancy of patients with mental disorders. Br J Psychiatry. 2011;199(6):453458.
45. Druss BG, Zhao L, Von ES, Morrato EH, Marcus SC. Understanding excess mortality in persons with mental illness: 17-year follow up of a nationally representative US survey. Med Care. 2011;49(6):599_ 604.

46. Khuwaja AK, Lalani S, Dhanani R, et al. Anxiety and depression among outpatients with type 2 diabetes: a multi-centre study of prevalence and associated factors. Diabetol Metab Syndr. 2010;2:72.

47. Collins MM, Corcorant P, Perry IJ. Anxiety and depression symptoms in patients with diabetes. Diabet Med. 2009;26:153-161.

48. Gehi A, Haas D, Pipkin S, Whooley MA. Depression and medication adherence in outpatients with coronary heart disease: findings from the Heart and Soul Study. Arch Intern Med. 2005;165(21):25082513.

49. Rieckmann N, Gerin W, Kronish IM, et al. Course of depressive symptoms and medication adherence after acute coronary syndromes: an electronic medication monitoring study. $\mathrm{J}$ Am Coll Cardiol. 2006;48(11):2218-2222.

50. Carliner H, Collins PY, Cabassa LJ, et al. Prevalence of cardiovascular risk factors among racial and ethnic minorities with schizophrenia spectrum and bipolar disorders: a critical literature review. Compr Psychiatry. 2014;55(2):233-247.

51. Bouwman V, Adriaanse MC, van 'T Riet E, et al. Depression, anxiety and glucose metabolism in the general Dutch population: the new Hoorn study. PLoS One. 2010;5:e9971.

52. Pan A, Keum N, Okereke OI, et al. Bidirectional association between depression and metabolic syndrome: a systematic review and metaanalysis of epidemiological studies. Diabetes Care. 2012;35(5):11711180.

53. Riba M, Wulsin L, Rubenfire M. Psychiatry and Heart Disease: The Mind, Brain, and Heart. Hoboken, NJ: Wiley-Blackwell; 2011.

54. Thombs BD, Bass EB, Ford DE, et al. Prevalence of depression in survivors of acute myocardial infarction. J Gen Intern Med. 2006;21 (1):30-38.

55. Mallik S, Spertus JA, Reid KJ, et al. Depressive symptoms after acute myocardial infarction: evidence for highest rates in younger women. Arch Intern Med. 2006;166(8):876-883.

\section{Publish your work in this journal}

Diabetes, Metabolic Syndrome and Obesity: Targets and Therapy is an international, peer-reviewed open-access journal committed to the rapid publication of the latest laboratory and clinical findings in the fields of diabetes, metabolic syndrome and obesity research. Original research, review, case reports, hypothesis formation, expert opinion and commentaries are all considered for publication. The manuscript management system is completely online and includes a very quick and fair peer-review system, which is all easy to use. Visit http://www.dovepress.com/testimonials.php to read real quotes from published authors. 